\title{
The effect of application of EDTA on the phytoextraction of heavy metals by Vetivera zizanioides, Cymbopogon citrates and Helianthus annuls
}

\author{
Yashim Zakka Israila", Agbaji Edith Bola, Gimba Casimir Emmanuel, Idris Suleiman Ola
}

Department of Chemistry, Ahmadu Bello University, Zaria, Nigeria

Email address:

ziyashim@abu.edu.ng (Yashim Z. I.), bola.agbaji@gmail.com (Agbaji E. B.), gimbace@yahoo.com (Gimba C. E.), alhajisoidris@yahoo.com (Idris S. O.)

\section{To cite this article:}

Yashim Zakka Israila, Agbaji Edith Bola, Gimba Casimir Emmanuel, Idris Suleiman Ola. The Effect of Application of EDTA on the Phytoextraction of Heavy Metals by Vetivera zizanioides, Cymbopogon citrates and Helianthus annuls. International Journal of Environmental Monitoring and Analysis. Vol. 3, No. 2, 2015, pp. 38-43. doi: 10.11648/j.ijema.20150302.12

\begin{abstract}
This study investigates the effect of the application of EDTA (ethylenediamine-tetraacetic acid) on the phytoextraction of $\mathrm{Cd}, \mathrm{Co}, \mathrm{Cu}, \mathrm{Ni}, \mathrm{Pb}$, and $\mathrm{Zn}$ by Vetivera zizanioides, Cymbopogon citrates and Helianthus annuls harvested from experimental site (with EDTA) and a control area (without EDTA) in Zaria-Nigeria. The concentrations of $\mathrm{Cd}$, $\mathrm{Co}$, $\mathrm{Cu}$, Ni, $\mathrm{Pb}$, and $\mathrm{Zn}$ in different parts of each of the plant species collected from the experimental and control soils were determined using atomic absorption spectrophotometry. Application of $5 \mathrm{mmol} / \mathrm{kg}$ EDTA in soil did not affect plant growth but significantly increased $\mathrm{Cd}, \mathrm{Co}, \mathrm{Cu}, \mathrm{Ni}, \mathrm{Pb}$, and $\mathrm{Zn}$ concentrations in shoots and roots of the plants. The concentrations of heavy metals measured in the tissues of plants collected from the experimental site were higher $(P \leq 0.05)$ than in the control. The percentage increase in the metal concentration for each plant specie were:- for Vetivera zizanioides, $\mathrm{Cd}-75 \%, \mathrm{Co}-205 \%, \mathrm{Cu}$ $-190 \%, \mathrm{Ni}-645 \%, \mathrm{~Pb}-5 \%$ and $\mathrm{Zn}-29 \%$; for Cymbopogon citrates, $\mathrm{Cd}-100 \%, \mathrm{Co}-109 \%, \mathrm{Cu}-551 \%, \mathrm{Ni}-907 \%, \mathrm{~Pb}-$ $39 \%$ and $\mathrm{Zn}-50 \%$; for Helianthus annuls, $\mathrm{Cd}-21 \%, \mathrm{Co}-235 \%, \mathrm{Cu}-44 \%, \mathrm{Ni}-507 \%, \mathrm{~Pb}-70 \%$ and $\mathrm{Zn}-02 \%$. The heavy metal concentrations were higher in leaves $(P \leq 0.05)$ than in roots of the plants. The translocation factor $(\mathrm{TF})$ for all the metals studied were greater than 1.The results of this study demonstrated that EDTA is an efficient soil amendment in enhancing desorption of $\mathrm{Cd}, \mathrm{Co}, \mathrm{Cu}, \mathrm{Ni}, \mathrm{Pb}$, and $\mathrm{Zn}$ from soil and in increasing their accumulation in plants. As for plant species tested, the effectiveness in the uptake of the metals studied was Helianthus annuls $<$ Vetivera zizanioides $<$ Cymbopogon citrates.
\end{abstract}

Keywords: Vetivera Zizanioides, Cymbopogon Citrates, Helianthus Annuls, EDTA, Translocation Factor, Phytoextraction

\section{Introduction}

Excessive metal concentration in soils pose significant hazard to human, animal and plant health, and to the environment in general [1].

Phytoextraction process involves plant roots removing metals from contaminated soils/sediments and transporting them to leaves and stems for harvesting and disposal without destroying the soil structure and fertility. The success of the phytoextraction process, whereby pollutants are effectively removed from soil, is dependent on an adequate yield of plants and/or the efficient transfer of contaminants from the roots of the plants into their aerial parts [2, 3]. Phytoextraction makes use of natural hyperaccumulators as well as high biomass producing plants. The two basic phytoextraction strategies that have been used are (i) chelate- assisted phytoextraction or induced phytoextraction, in which artificial chelates are added to treated soil to increase the mobility and uptake of metal contaminants and (ii) continuous phytoextraction, in which the removal of metal depends on the natural physiological ability of the plant [4]. Plant species and relative abundance and availability of necessary elements also control metal uptake rates.

Ethylenediamine-tetraacetic acid (EDTA), a synthetic chelator, is poorly biodegraded in soils although it is effective at complexing metals. It is a non-selective extracting agent that can form a strong complex with a variety of metals in soils including alkaline-earth cations. Excess amounts of EDTA may leach to groundwater and cause subsurface water contamination. Wallace et al. [5] reported that metal-EDTA complexes could increase solubility and phytoavailability of metals in soils. When EDTA is applied to soils, a large 
fraction of the total metals is dissolved and becomes available for phytoextraction without inducing a strong acidification of the growth medium. Furthermore, as compared to other chemical compounds (such as inorganic acids), EDTA can solubilize metals with fewer undesirable effects on the soil physico-chemical properties. The ability of EDTA to increase concentration of metals in soil solution is influenced by a number of factors, including: concentration of metals and EDTA; presence of competing cations; metal species and their distribution among soil fractions; soil $\mathrm{pH}$; adsorption of free and complexed metals onto charged soil particles and the formation constant of metal-ligand complexes. Because of its high binding affinity for metals, when applied at high concentrations, EDTA has the potential to affect the release of metals from solid phases by forming dissolved complexes. The formation of metal-EDTA complexes in soil solution may shift precipitation and sorption equilibria toward increased dissolution of metals [6]. Alternatively, EDTA may interact directly with solid phases by complexing metal ions present in, and/or adsorbed onto primary or secondary minerals [7].

The dumpsite at Dakace in Zaria, Nigeria $\left(11^{\circ} 07^{\prime} 51^{\prime \prime} \mathrm{N}\right.$; $7^{\circ} 43^{\prime} 43^{\prime \prime}$ E) occupies an estimated area of $20 \mathrm{~m} \mathrm{x} 6 \mathrm{~m}$. Three different plant species namely Vetivera zizanioides, Cymbopogon citrates (Lemon grass) and Helianthus annuls (sunflower) were planted on the soil around the dumpsite.

The aim of this study is to investigate the effect of the application of EDTA (ethylenediamine-tetraacetic acid) on the phytoextraction of $\mathrm{Cd}, \mathrm{Co}, \mathrm{Cu}, \mathrm{Ni}, \mathrm{Pb}$, and $\mathrm{Zn}$ by Vetivera zizanioides, Cymbopogon citrates and Helianthus annuls collected from experimental site (with EDTA) and a control area (without EDTA) in Zaria-Nigeria.

\section{Materials and Methods}

\subsection{Experimental Design}

The field experiment was carried out near a scrap-metal dumpsite at Dakace in Zaria-Nigeria from July to September of 2013. An experimental area of $6 \mathrm{~m} \mathrm{x} 4 \mathrm{~m}$ was selected at each site and divided into two parts $(3 \mathrm{~m} \times 2 \mathrm{~m})$ where the studied plants were grown. The seedlings of the plants were obtained from farmlands not contaminated and transplanted to the field. The seedlings of the plants were obtained from farmlands not contaminated and transplanted to the field. Three different plant species-Vetivera zizanioides, Cymbopogon citrates (Lemon grass) and Helianthus annus (sunflower) were planted in the designated field plot with spacing of $20 \mathrm{~cm} \times 20 \mathrm{~cm}$ for all the tested plants as described by Zhuang et al. [8]. The plants were allowed to grow naturally under natural agro-climatic conditions and exposed to natural day and night temperatures, with neither fertilization nor optimum irrigation so as to assess the feasibility of the remediation process. Weeds were controlled by mechanical method. After 10 weeks when the plants must have achieved maximum biomass production, a single dose of $5 \mathrm{mmol} / \mathrm{kg}$ EDTA $\left(\mathrm{Na}_{2}\right.$-EDTA) was applied to the soil of one part of the plot. Seven days after the application of the EDTA solution, the plants were harvested and the associated soil samples were collected.

\subsection{Sample Collection}

Whole plant samples were collected from experimental site (with EDTA), while soil samples (150 g) were collected from the surface to a depth of $15 \mathrm{~cm}$ around each plant root zone, using hand trowel and then mixed together. Background soil (150 g) and plant samples (without EDTA) were also obtained as control from an area $5 \mathrm{~km}$ distance away from the dumpsite. The collection was done by dividing the experimental and control sites each into four quadrants, five plants samples and soil samples were collected from each quadrant in a diagonal basis following the methods of Nuonom et al. [9].

\subsection{Sample Treatment and Analysis}

The collected soil samples were air-dried at room temperature for 3 days, while the shoots and roots of the plant samples were washed, separated and air dried. The soil samples were ground and sieved $(500 \mu \mathrm{m}$ sieve) and then dried in an oven at $65 \pm 1{ }^{\circ} \mathrm{C}$ for $16 \mathrm{hrs}$, following which it was kept in clean polythene bags for further analysis.

One gram of each of the soil and plant samples was digested separately with $10 \mathrm{~cm}^{3}$ of aqua regia (a mixture of 3 parts concentrated $\mathrm{HCl}$ to 1 part concentrated $\mathrm{HNO}_{3}$ ) on a hot plate in a fume cupboard, until a clear solution was obtained. Distilled water was added periodically to avoid drying up of the digest. To the hot solution, $30 \mathrm{~cm}^{3}$ of distilled water was then added and filtered through a Whatman No. 42 filter paper into a $50 \mathrm{~cm}^{3}$ standard volumetric flask and then made up to the mark with distilled water [10].

Cadmium, cobalt, copper, nickel, lead and zinc concentrations in the plant and soil samples were determined using a D100XB4J atomic absorption spectrometer [9], with the analyses being done in triplicate.

The bioaccumulation factor $(\mathrm{BF})$ and the translocation factor (TF) were calculated to determine the degree of metal accumulation in the plants grown at the farm site close to the dumpsite.

$$
\begin{gathered}
\mathrm{BF}=\frac{\text { Concentration of metal in plant }}{\text { Concentration of metal in soil }} \\
\mathrm{TF}=\frac{\text { Concentration of metal in plant shoot }}{\text { Concentration of metal in plant root }}
\end{gathered}
$$

Replicates of the data obtained were subjected to one-way ANOVA using SPSS 20 software.

\section{Results and Discussion}

Figure Ia shows the results for the metal concentrations in the different parts of Vetivera zizanioides plant. The results showed that the concentrations of the metals in the plant at 
the experimental site (with EDTA) were higher $(P \leq 0.05)$ than the control (without EDTA).

The metal levels were higher in the leaves $(P \leq 0.05)$ than in the roots which is an indication that the studied metals were extracted from the soil by the roots and translocated to the leaves. The application of EDTA has increased the metals levels as follows: $\mathrm{Cd}-75 \%, \mathrm{Co}-205 \%, \mathrm{Cu}-190 \%, \mathrm{Ni}-$ $645 \%, \mathrm{~Pb}-5 \%$ and $\mathrm{Zn}-29 \%$. The bioaccumulation factor, $\mathrm{BF}$ (Figure Ib) for all the metals studied was greater than 1, except $\mathrm{Cd}$ whose $\mathrm{BF}$ was less than 1 . The translocation factor (TF) for the studied metals were all greater than 1. For Cymbopogon citrates (Figure IIa) the metal levels at the experimental site (with EDTA) were higher $(P \leq 0.05)$ than the control (without EDTA). The percentage increase were: $\mathrm{Cd}-100 \%, \mathrm{Co}-109 \%, \mathrm{Cu}-551 \%, \mathrm{Ni}-907 \%, \mathrm{~Pb}-39 \%$ and $\mathrm{Zn}-50 \%$. There was an increase in both $\mathrm{BF}$ and $\mathrm{TF}$ at the experimental site (with EDTA) compared to the control (without EDTA), except for $\mathrm{Pb}$ where the TF were the same (Figure IIb). For Helianthus annuls (Figure IIIa) the metal levels at the experimental site (with EDTA) were also higher $(P \leq 0.05)$ than the control (without EDTA). The percentage increase for the studied metals was: $\mathrm{Cd}-21 \%$, $\mathrm{Co}-235 \%$, $\mathrm{Cu}-44 \%, \mathrm{Ni}-507 \%, \mathrm{~Pb}-70 \%$ and $\mathrm{Zn}-02 \%$. Both the $\mathrm{BF}$ and the TF were greater than 1 (Figure IIIb), except for $\mathrm{Cd}$ where its BF was less than 1.

Huang et al. [11] and Blaylock et al. [12] were able to achieve rapid accumulation of $\mathrm{Pb}$ in plant shoots higher than $1 \%$ of shoot dry biomass with EDTA, the most commonly used chelating agent. Heavy metal concentration in shoots and roots of plants significantly increased when EDTA addition levels were higher than $3 \mathrm{mmol} / \mathrm{kg}$ [13]. Chelating agent not only facilities heavy metal removal from the soil via plant uptake; it theoretically means that any metal that can be chelated and solubilized, can be removed in the same manner, providing that the soil chemistry favors the forming of a chelate metal complex [14].

These results indicated that the application of EDTA increased the studied metal accumulation in plant roots from the rhizosphere of the soil, and also facilitated the metal translocation from roots to shoots. The phytoextraction potential of each plant specie is determined by its BF and TF. Where the BF is greater than 1 , the plant specie is a good accumulator, and where the TF is greater than 1 the plant specie is a hyperaccumulator of the metal [15]. As for plant species tested, the effectiveness in the uptake of the metals studied was Cymbopogon citrates $>$ Vetivera zizanioides $>$ Helianthus annuls. These plants have good phytoextraction potentials for the removal of heavy metals from contaminated soils.

\section{Conclusion}

The concentrations of the metals in Cymbopogon citrates, Vetivera zizanioides, Helianthus annuls plants at the experimental site (with EDTA) were higher than the control (without EDTA). The metal levels were higher in the leaves than in the roots which is an indication that the studied metals were extracted from the soil by the roots and translocated to the leaves. The application of EDTA increased the metal accumulation of studied plant roots from the rhizosphere of the soil, and also facilitated the metal translocation from roots to shoots. The percentage increase ranged from $39 \%$ in $\mathrm{Pb}$ to about $907 \%$ in $\mathrm{Ni}$ for Cymbopogon citrates, $5 \%$ in $\mathrm{Pb}$ to $645 \%$ in $\mathrm{Ni}$ for Vetivera zizanioides and $2 \%$ in $\mathrm{Zn}$ to about $507 \%$ in $\mathrm{Ni}$ for Helianthus annuls. As for plant species tested, the effectiveness in the uptake of the metals studied was Cymbopogon citrates $>$ Vetivera zizanioides $>$ Helianthus annuls.

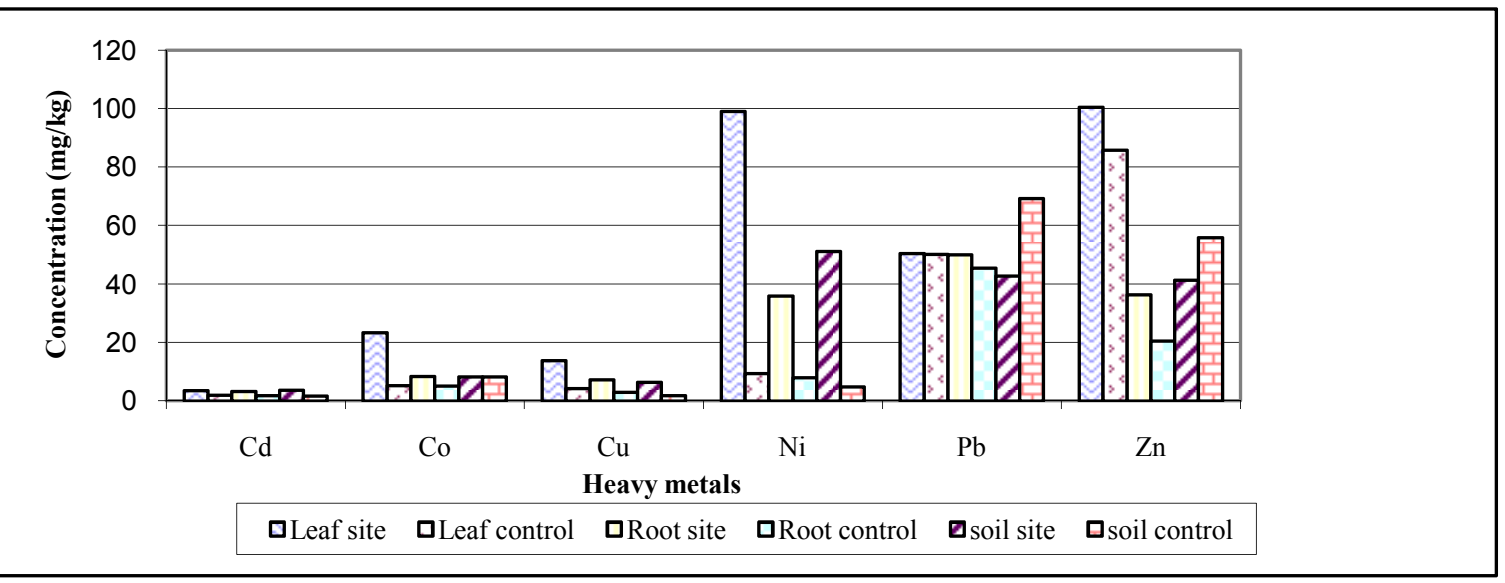

Figure Ia. Concentration of Heavy metals ( $\mathrm{mg} / \mathrm{kg}$ ) in different parts Vetivera zizanioides plant and the soil. 


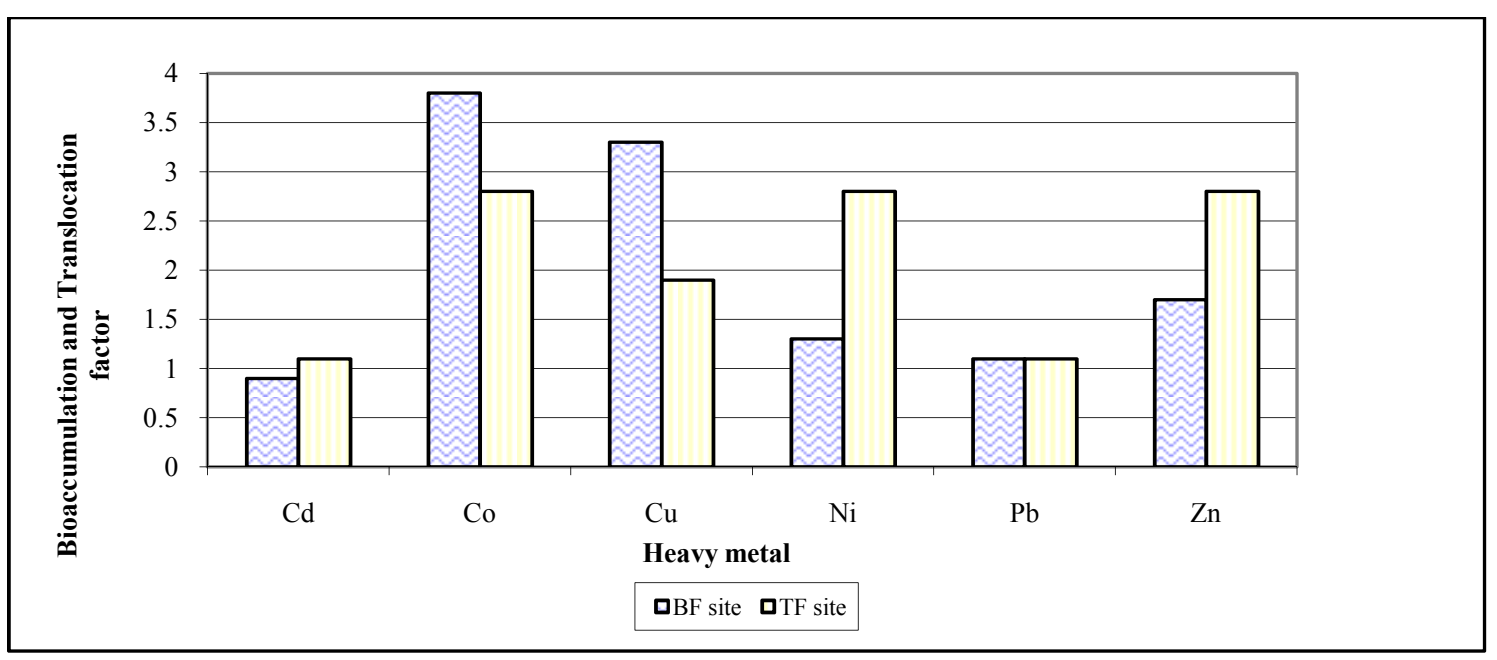

Figure Ib. Bioaccumulation and Transfer factors for Vetivera zizanioides plant.

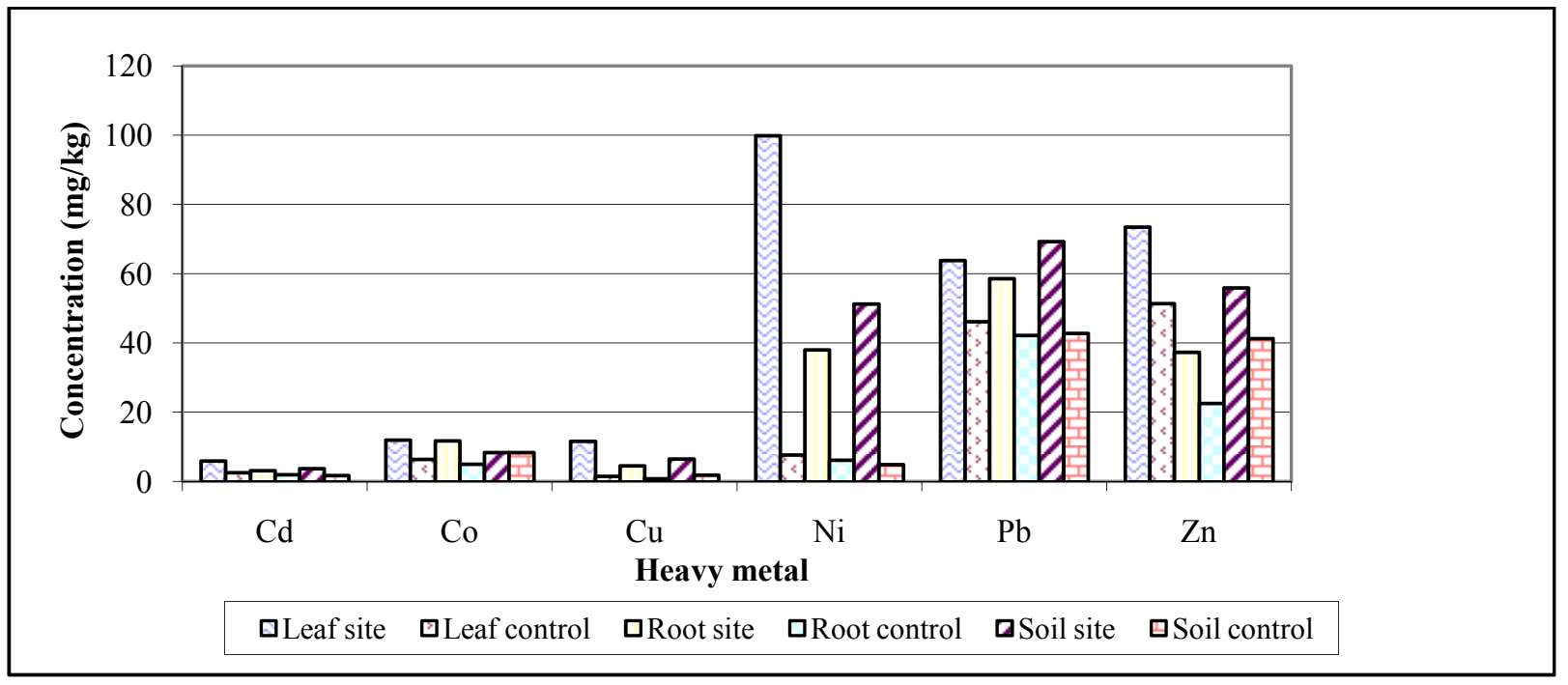

Figure IIa. Concentration of Heavy metals (mg/kg) in different parts Cymbopogon citrates(Lemon grass) plant and the soil.

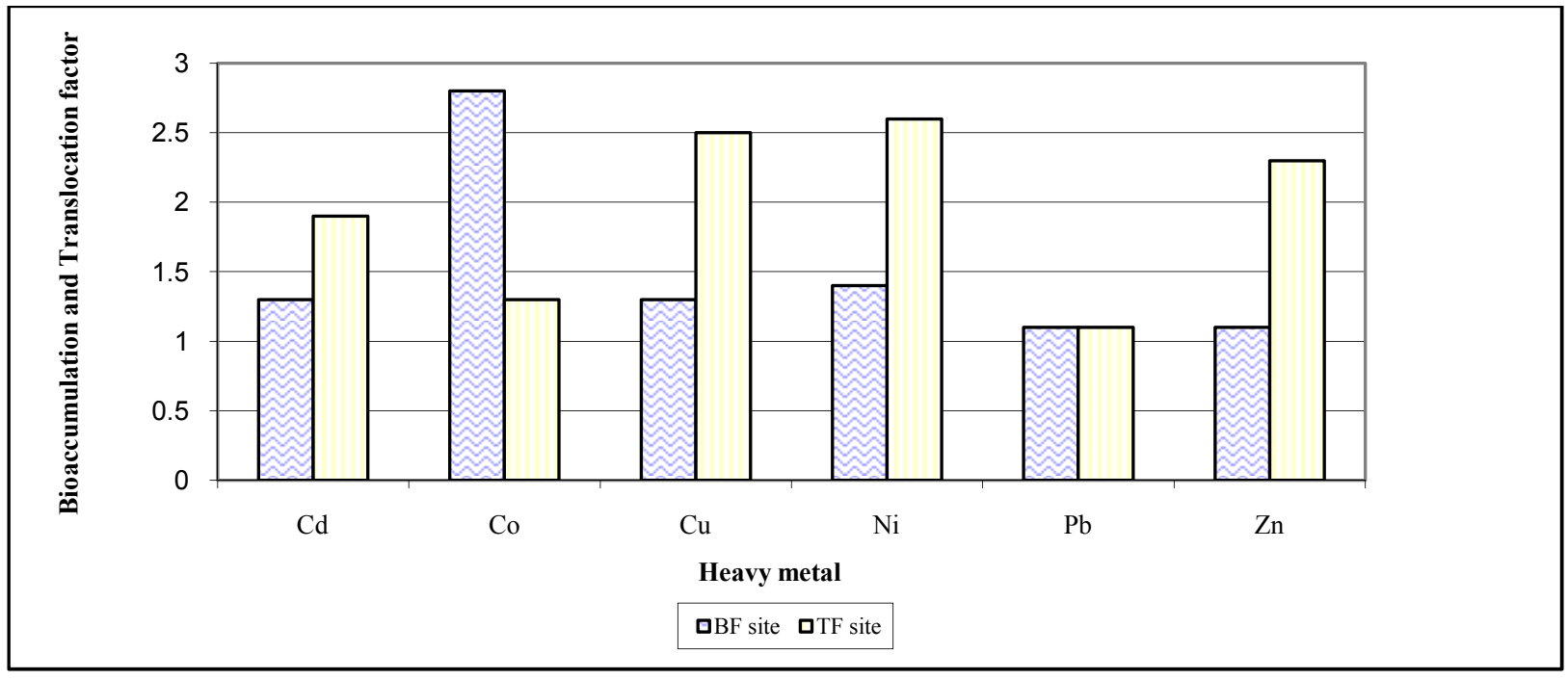

Figure IIb. Bioaccumulation and Transfer factors for Cymbopogon citrates(Lemon grass) plant. 


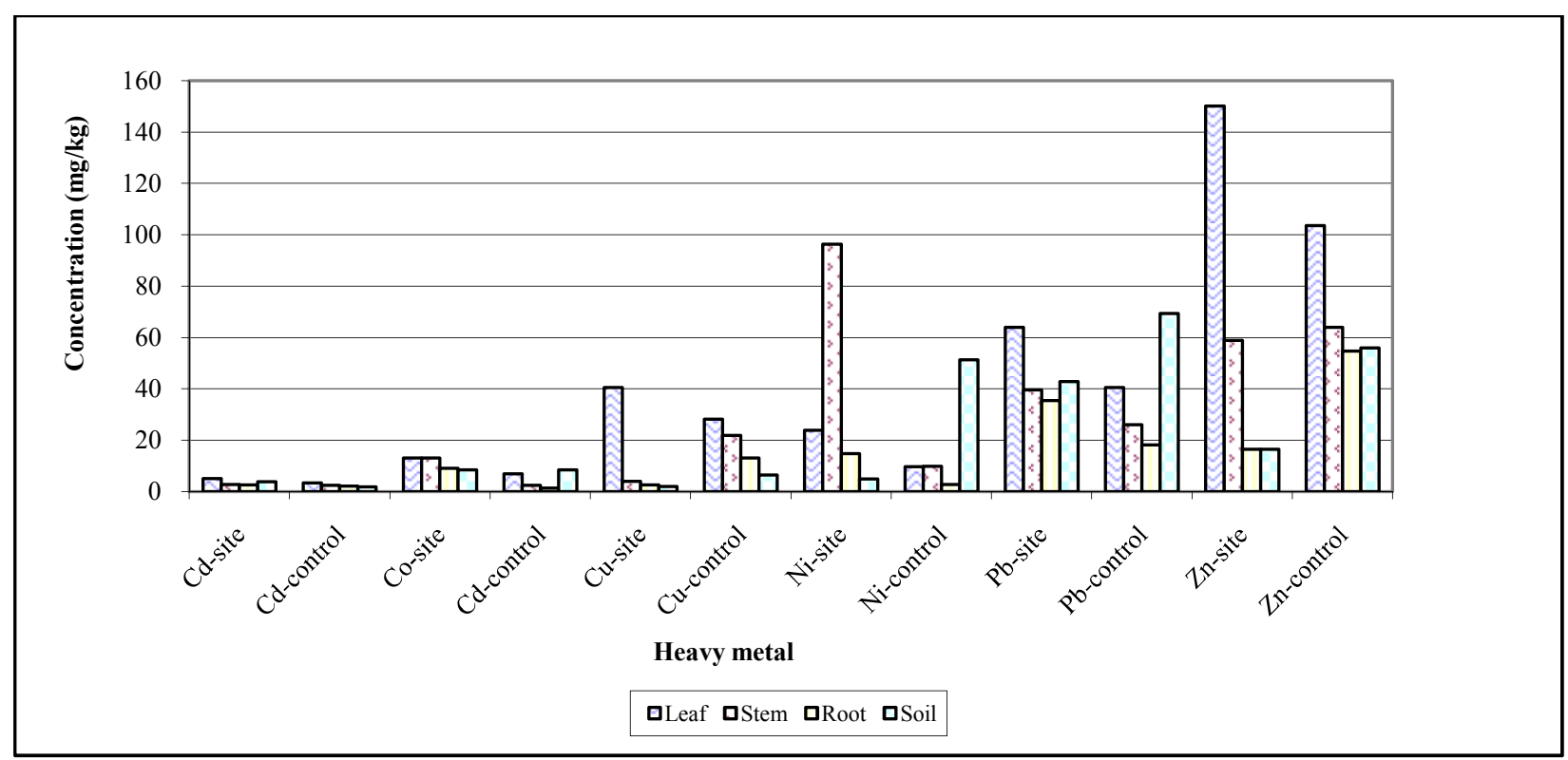

Figure IIIa. Concentration of Heavy metals $(\mathrm{mg} / \mathrm{kg})$ in different parts Helianthus annuls (sunflower) plant and the soil.

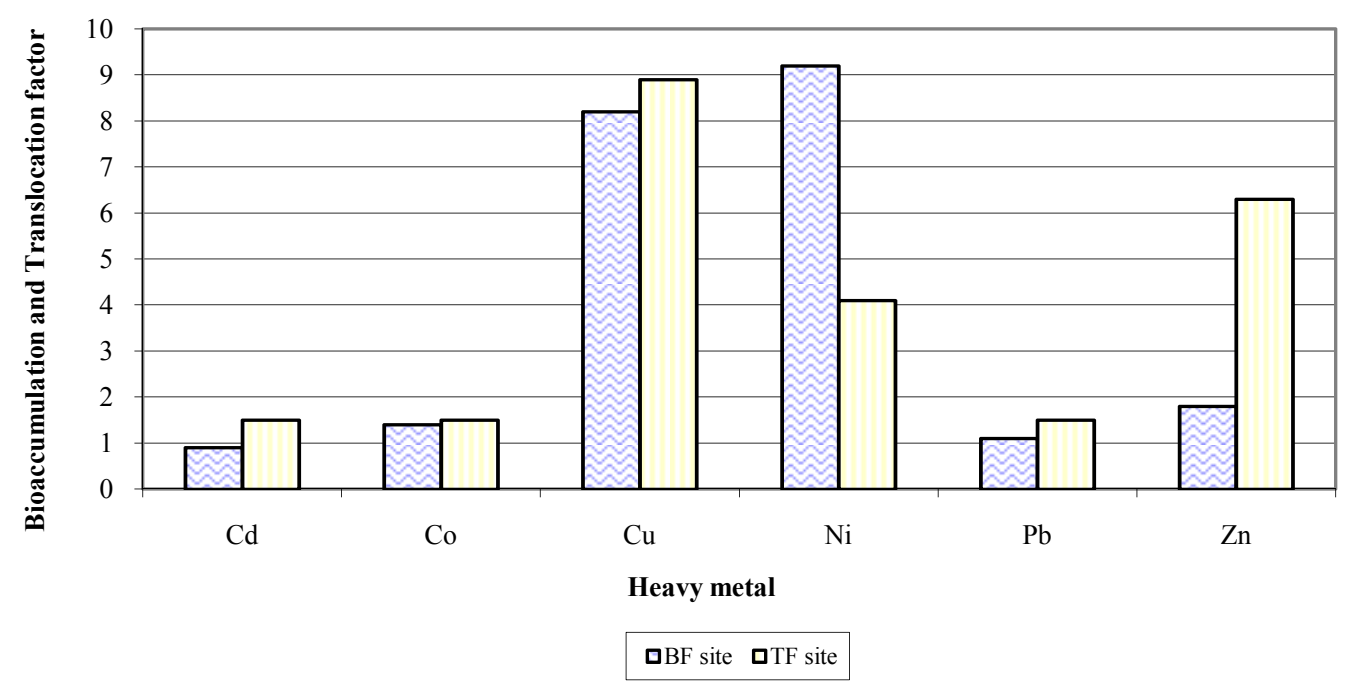

Figure IIIb. Bioaccumulation and Transfer factors for Helianthus annuls (sunflower) plant.

\section{References}

[1] Nascimento, C. W. A. and Xing, B. Phytoextraction: A review on enhanced metal availability and plant accumulation. Science Agricutre. 2006; 63(3):299-311.

[2] Luo, C. L., Shen, Z. G., Li, X. D. Enhanced phytoextraction of $\mathrm{Cu}, \mathrm{Pb}, \mathrm{Zn}$ and $\mathrm{Cd}$ with EDTA and EDDS. Chemosphere. 2005, 59: 1-11.

[3] Evangelou, M. W. H., Ebel, M. and Schaeffer, A. Chelate assisted phytoextraction of heavy metals from soils. Effect, mechanism, toxicity, and fate of chelating agents. Chemosphere, 2007, 68: 989-1003.

[4] Saifullah, A., Meers, E., Qadir, M., de Caritat, P., Tack, F.M.G., $\mathrm{Du}$ Laing, G. and Zia, M.H. EDTA-assisted Pb phytoextraction. Chemosphere. 2009, 74: 1279-1291.
[5] Wallace, A., Muller, R. J., Cha, J. W., Alexander, G. V. Soil pH excess lime and chelating agent on micronutrients in soybeans and bushbeans. Agron. J. 1974;66:698-700.

[6] Dushenkov, S., Kapulnik, Y., Blaylock, M. J., Sorochinsky, B., Raskin, I. and Ensley, B. Phytoremediation: a novel approach to an old problem. In: Wise, D. L. (Ed.),Global Environmental Biotechnology. Elsevier, Amsterdam, The Netherlands, 1997.

[7] Gonsior, S. J., Sorci, J. J., Zoellner, M. J. and Landenberger, B. D. The effects of EDTA on metal solubilization in river sediment/water systems. J. Environ. Qual.1997; 26: 957-966.

[8] Zhuang, X. L.; Chen, J.; Shim, H. and Bai, Z. New advances in plant growth promoting rhizobacteria for bioremediation. Environ. Int. 2007, 33: 406-413

[9] Nuonom, L., Yemefack, M., Techienkwa, M. and Njongang, R. Impact of natural fallow duration on Cameron. Nigerian Journal of Soil Research. 2000; 3: 52-57. 
[10] Kisku. G. C., Barman. S. C. and Shargava, S. K. Contamination of Soil and plants with PTE Irrigated with mixed industrial effluent and its impact on the a environment. Water, Air and Soil Pollution. 2000;120. $121-137$.

[11] Sun, Y., Zhou, Q., Xu, Y., Wang, L. and Liang, X. (2011): The role of EDTA on Cadmium phytoextraction in a Cadmiumhyperaccumulator Rorippa globosa. Journal of Environmental Chemistry and Ecotoxicology. 3(3). 45-51.

[12] Huang, J. W., Chen, J., Berti, W. R. and Cunnigham, S. D. Phytoremediation of lead-contaminated soils: Role of synthetic chelates in lead phytoextraction. Environ. Sci. Technol. 1997; 31: 800-805.
[13] Blaylock M.J., Salt D.E., Dushenkov S., Zakharova O., Gussman C., Kapulnik Y., Ensley B.D., Raskin I. Enhanced accumulation of $\mathrm{Pb}$ in Indian mustard by soil-applied chelating agents. Environ. Sci. Technol. 1997; 31: 860-865.

[14] Turan, M. and Esringü, A. Phytoremediation based on canola (Brassica napus L.) and Indian mustard (Brassica juncea L.) planted on spiked soil by aliquot amount of $\mathrm{Cd}, \mathrm{Cu}, \mathrm{Pb}$, and Zn. Plant Soil Environ. 2007; 53(1): 7-15

[15] Baker, A. J. M. and Brooks, R. R. terrestrial higher plants which hyperaccumulate metallic elements - A review of their distribution, ecology and phytochemistry. Biorecovery. 1989; 1: $81-126$. 